Hispania, 2014, vol. LXXIV, $\mathrm{n}^{\circ}$. 247, mayo-agosto, págs. 357-384

ISSN: 0018-2141, e-ISSN: 1988-8368, doi: 10.3989/hispania.2014.011

\title{
Antigua disciplina: el ejemplo romano en los tratados militares ibéri- cos, c. 1560-1600 1
}

\author{
Saúl Martínez Bermejo \\ CHAM, Universidade Nova de Lisboa y Universidade das Açores
}

RESUMEN: La historia militar y la imagen imperial de Roma proporcionaron un marco de referencia fundamental para concebir el papel estratégico del ejército en las monarquías portuguesa y española de la Edad Moderna. Un elemento clave del pensamiento militar de este momento fue la disciplina. Este término refería tanto a la creciente profesionalización y estandarización de la práctica bélica (así como del propio entrenamiento disciplinado) como al desarrollo de un conjunto de saberes específicos sobre la guerra. Este artículo analiza la importancia de Roma en la configuración de la disciplina militar a través del análisis de las reflexiones, reclamaciones y propuestas de reforma de los numerosos autores militares ibéricos de la época. El objetivo que se persigue es doble: la identificación y análisis de un discurso romano particular y la contextualización del género literario de las artes militares como una manifestación cultural cuya importancia e influencia trasciende los límites de la historia militar.

\section{PALABRAS CLAVE: Cultura militar; tratados militares; disciplina ro- mana; recepción; ejemplo clásico.}

\section{Ancient discipline: Roman example in Iberian Military Treatises, c. 1560-1600}

ABSTRACT: The military history and the imperial image of Rome offered an essential framework for conceiving the strategic role of the army in the early modern Portuguese and Spanish monarchies. "Disciplina» (discipline) was a key element of the military thought of the epoch. The term referred not

1 Este trabajo es parte del proyecto EMPIRECLASSICS; IEF-Marie Curie 275853. Agradezco a las compañeras y compañeros del Fórum Postdoc del CHAM sus múltiples indicaciones - especialmente a Edval de Souza Barros, que hizo una lectura profunda y numerosas sugerencias de mejora del texto- y a James Amelang, que también leyó y comentó atentamente la primera versión del mismo. 
only to the growing professionalization and standardization of military practices (such as drill itself), but also to the development of a specific field of knowledge regarding war. This article analyses the works of several Portuguese and Spanish military authors of the period and the importance of Rome in their reflections and proposals. The article's objective is twofold: to identify and analyse a particular kind of "Roman" discourse and to contextualize the literary genre of martial arts as a cultural phenomenon whose significance goes considerably beyond the limits of military history.

KEY WORDS: Military culture; military treatises; Roman discipline; reception; Classical exemplars.

\section{INTRODUCCIÓN}

Para el Maestre de Campo español Sancho de Londoño no había duda alguna de que observar las leyes de la disciplina «hizo a Roma señora del mundo», y «haria a la nacion Española invincible» ${ }^{2}$. El clérigo Bernardino de Escalante era de la misma opinión. Para él, un ejército bien ordenado había permitido a Roma «estender sus Señorios, y sujetar muchas naciones de gentes barbaras e indomitas» y ese debía ser el ejemplo a seguir para la gran Monarquía católica, dividida y extendida por todo el mundo ${ }^{3}$. Juan de Carrión Pardo, otro soldado español de la segunda mitad del siglo XVI, consideraba — siguiendo la misma línea comparativa - que tras los romanos habían «succedido los Españoles, o por mejor dezir permanecido, cuyo arte y proceder en la Milicia guardamos $\rangle^{4}$. La retórica de estos tres autores muestra que Roma fue sinónimo de poder militar y dominio político y un referente omnipresente en la Edad Moderna. Su historia ofrecía un inagotable repertorio de ejemplos de tácticas bélicas, hazañas militares y de soldados y capitanes valerosos.

El objetivo de este artículo es analizar el modo en que el referente romano y la comparación histórica fueron empleados para conceptualizar el desarrollo del saber militar durante las últimas cuatro décadas del siglo XVI. Durante esos cuarenta años, la expansión de las Monarquías española y portuguesa y las diversas guerras europeas contribuyeron a la consolidación de un campo de saber específico, en que se ocuparon no sólo los militares, sino también los estadistas y políticos de la época. Debido a las constantes necesidades prácticas de organización de los ejércitos, desde los entrenamientos a la logística o las tácticas, la guerra adquirirá una importancia teórica y cultural clave. La recepción y uso del modelo romano sirvió para la defensa de determinados

\footnotetext{
2 LONDOÑO, 1589: fol. 6v. Ver GARCÍA HERNÁN, 22 (Alicante, 2004): 7-72.

${ }^{3}$ ESCALANTE, 1583: «Al illustrissimo señor Cardenal Don Rodrigo de Castro».

${ }^{4}$ CARRIÓN PARDO, 1595: fol. 10r.
} 
cursos de acción y para la expresión, en términos más amplios, del papel militar de las Monarquías ibéricas.

El núcleo del corpus documental aquí empleado lo constituye más de una veintena de tratados militares, publicados por autores españoles y portugueses durante el periodo que va entre 1560 y 1600 aproximadamente. Repasaré en primer lugar las características particulares de este género literario y el modo en que los autores militares concibieron su tarea para explicar el papel que la lectura y la recepción de los clásicos tuvieron en los ejércitos de la época. En un segundo apartado, examinaré detalladamente el uso del ejemplo romano para conducir la discusión en torno al disciplinamiento del ejército. Mostraré también que el ejemplo de Roma servía para concebir otros problemas y necesidades de los ejércitos del momento. En tercer lugar analizaré algunas de las contradicciones derivadas de la comparación histórica entre estas dos épocas tan alejadas en el tiempo y cómo pudieron convivir innovación técnica y ejemplo romano.

Los estudios sobre historia militar han desarrollado un creciente interés por comprender los ejércitos como un fenómeno de alcance social y económico más amplio, y se han investigado cuestiones relacionadas con la extracción social de los reclutas, la logística de la financiación y el abastecimiento, el impacto de la guerra y otras 5 . En lo que respecta a las artes militares, en 2003 Antonio Espino López recordaba aún la poca atención que había recibido esta tratadística y señalaba la necesidad de investigar lo que denominaba «cultura militar», un campo en el que incluía tanto las motivaciones de los autores de estas obras como las influencias que este tipo de escritos podían tener en la sociedad $^{6}$. No obstante, en la última década la literatura militar ibérica ha sido objeto de atención por autores como el propio Espino ${ }^{7}$, Rui Bebiano ${ }^{8}$, Ricardo González Castrillo ${ }^{9}$, Esther Merino Peral ${ }^{10}$ o Fernándo González de León, quien ha denunciado recientemente la escasa importancia que la historia cultural, artística o política presta al fenómeno militar en un sentido más amplio $^{11}$. El lenguaje romano era precisamente, como trataré de mostrar, uno de los medios por los que se expresaron las conexiones e implicaciones culturales y políticas más generales de la guerra.

5 BLACK, 2002; 2004. GARCÍA HERNÁN y MAFFI, 2006. JIMÉNEZ ESTRELLA y ANDÚJAR CASTILLO, 2007. LAWRENCE, 2009. PARKER, 69/1 (Lexington, 2005): 205209. THOMPSON, 21 (Barcelona, 2003): 17-38. WHITE, 9/1 (Great Bardfield, Essex, 2002): 1-38; 21 (Barcelona, 2003): 63-93.

${ }^{6}$ ESPINO LÓPEZ, 21 (Barcelona, 2003): 161-191.

${ }^{7}$ ESPINO LÓPEZ, 2001: 16-17.

${ }^{8}$ BEBIANO, 9/10 (Lisboa, 1993): 83-98; 1997.

9 GONZÁLEZ CASTRILLO, 2000.

${ }^{10}$ MERINO PERAL, 2002.

11 GONZÁLEZ DE LEÓN, 2009: 5; 27/1 (Kirksville, 1996): 61-85. 


\section{LAS ARTES MILITARES COMO GÉNERO LITERARIO: CIENCIA, PRÁCTICA Y BIOGRAFÍA}

Las artes militares publicadas por autores portugueses y españoles en la segunda mitad del siglo XVI forman parte de un conjunto mucho mayor de tratados y reflexiones sobre la guerra a escala europea. Su conexión con este universo mayor se hace explícita en las referencias a otros ejércitos europeos y extraeuropeos, así como a diversos autores italianos, franceses u otros ${ }^{12}$. Las artes militares constituyen además un corpus heterogéneo, pues dependiendo del interés y los conocimientos de sus distintos autores, se abordan en ellas cuestiones tan variopintas como la guerra en el mar, la caballería, la organización general de los ejércitos de las Monarquías hispana y portuguesa en términos financieros y políticos, etc. En este conjunto destacan las reflexiones sobre la infantería moderna - encuadradas en obras generales sobre la guerra- y un grupo específico de obras dedicadas a la técnica de la fortificación y las obras sobre artillería ${ }^{13}$.

En estas artes, las particulares lecturas de los ejemplos clásicos se combinan con saberes y necesidades prácticas y técnicas. Las experiencias personales de primera mano tienen también un peso importante en estas obras, pues la expresión de conocimientos militares se cruza constantemente con las exigencias del presente. Otra característica propia del género es su carácter misceláneo y acumulativo, debido en parte a que las fuentes clásicas sobre la historia militar se leyeron y editaron a la vez que la tratadística moderna. Anglo ha mostrado a este respecto la doble circulación del Arte della guerra de Maquiavelo (1521) y las fuentes clásicas en que se inspiraba ${ }^{14}$, y el De re militari de Diego Gracián (1566) es un ejemplo de obra híbrida compuesta de traducciones de Onosandro, de extractos comentados de las obras de César y una versión castellana de Guillaume Du Bellay, que por su parte contenía numerosas referencias y comparaciones con los ejércitos griegos y romanos ${ }^{15}$. Cada una de estas artes constituye por lo tanto una mezcla particular entre ciencia (un término que engloba aquí todo conocimiento teórico y libresco), práctica y biografía ${ }^{16}$.

Sus autores eran, por lo general, militares y su aproximación personal al fenómeno se diferenciaba del estudio anticuario o erudito ${ }^{17}$. De hecho, el de-

12 VERRIER, 1997: 20, identifica las interacciones y conexiones propias del «cosmopolitismo militar».

${ }^{13}$ Una versión más cuantitativa en ESPINO LÓPEZ, 2001: 411

14 ANGLO, 2005: 437.

15 GRACIÁN, 1566. BELLAY, 1548: fols. 11r-13r, 28r-29r, 32v, 49v, 68r.

${ }^{16}$ La heterogeneidad y el carácter híbrido de la literatura militar en CASSOL, 2000: 51. Una descripción complementaria del género en la segunda mitad del XVII en MARTÍNEZ OYARZÁBAL, 2006.

17 Datos más detallados en ESPINO LóPEZ, 2001: 420. 
sarrollo del género a lo largo del siglo XVI trajo consigo la conformación de un escritor militar ideal ${ }^{18}$. Eran comunes las referencias a la humildad del autor, a la lógica del servicio general («alguma satisfação á minha patria», que dirá Luís Mendes de Vasconcellos) y otros tópicos habituales en el establecimiento del ethos del autor de la Edad Moderna. El alférez Juan de Funes, un ejemplo de cómo los autores militares proliferaron en todos los escalones de la jerarquía, aunó otros dos tópicos habituales en la época: el de los «ratos desocupados» y el los amigos que lo «importunaron» a imprimir su libro ${ }^{19}$. Junto a estas representaciones encontramos otras más específicas del género militar. Texto tras texto se representa a un militar que, forzado por algún accidente físico, por su edad, o por otras circunstancias, se ve empujado a escribir e imprimir sobre la propia disciplina que ha practicado y a suspender o descansar de sus actividades cotidianas del ejército.

Tras señalar que había servido a los monarcas hispanos más de treinta años en guerras y embajadas, Bernardino de Mendoza indicaba en sus Comentarios (1592) tener "casi del todo perdida la vista» y «no poder hazer ya a V. Alt. otro servicio que el de los archivos» ${ }^{20}$. La «temprana ceguera» de Mendoza justificaba también la presentación de su Theorica y practica de la guerra (1595) como un servicio al rey hecho por escrito ${ }^{21}$. El alférez vizcaíno Martín de Eguiluz refería en su Milicia, discurso y regla militar a su poco entendimiento, su larga experiencia de veinticuatro años como militar y su voluntad de continuar sirviendo a Felipe II. También decía haber escrito en «forçada ocasion», señalando que de no haber sufrido cinco meses de presidio en el Castillo de Milán, «dudo que me huviera ocupado en esto»22.

En ocasiones, personajes que no eran exactamente militares se apropiaron activamente de esta presentación estandarizada. La primera razón por la que Bernardino de Escalante, clérigo, justificaba haber escrito sus Diálogos del arte militar (1583) era por haberse «criado desde mi niñez en ella», en casa de su padre el capitán García de Escalante ${ }^{23}$. El portugués Fernando Oliveira, también clérigo, aunque con una larga experiencia como marino, justificaba la escritura de su Arte da guerra no mar (1555) indicando que «aos sacerdo-

${ }^{18}$ La doble (e híbrida) naturaleza de personaje-soldado (literario) y autor-soldado en CASSOL, 2000: 37. Sobre la naturaleza de autores, lectores y artes militares de la Antigüedad, ver CAMPBELL, 2004.

${ }^{19}$ FUNES, 1582. Para el uso general de estos tópicos, ver SAUNDERS, 1 (Oxford, 1951).

${ }^{20}$ MENDOZA, 1592: sign. fol. $3 \mathrm{v}$.

${ }^{21}$ MENDOZA, 1592: sign. fol. $2 \mathrm{v} ; 1596$.

22 EGUILUZ, 1595: fol. 43v.

${ }^{23}$ ESCALANTE, 1583: «A los muy illustres Señores la Infanteria Española [...]». 
tes convem ir aa guerra quanto mays falar della», si bien aclaraba que sus armas debían ser las lágrimas y las oraciones ${ }^{24}$.

Las artes militares fueron en gran medida el resultado de un modo particular de escritura; eran memoriales que albergaban las esperanzas de recibir mercedes por parte del rey en contrapartida a los servicios prestados. Alessandro Cassol ha analizado las complejas fronteras entre papel de servicio y autobiografía ${ }^{25}$ y esta lógica de servicio y recompensa ha sido señalada también por Raffaele Puddu ${ }^{26}$ y John Hale, para quien los autores militares buscaban fama, reputación y apoyo en forma de un trabajo o una compensación monetaria ${ }^{27}$. Este era claramente el objetivo de Bartolomé Scarion de Pavia, que además de definirse a sí mismo como «soldado de muchos años» mencionó explícitamente haber sufrido «mucha costa y gasto de hazienda» en su viaje hasta Lisboa ${ }^{28}$. El Cuerpo enfermo de la milicia española mezcla el tono autobiográfico empleado por Marcos de Isaba, con la petición de mercedes por parte de su cuñado Miguel Guerrero de Caseda, encargado de acabar e imprimir la obra tras la muerte de aquél. Isaba indicaba que a pesar de que muchos «ilustres varones» antiguos y modernos habían escrito sobre el arte militar, él haría «memoria» de algunas cuestiones relevantes ${ }^{29}$. Guerrero de Caseda exponía en cambio el largo proceso de publicación de la obra, su paso por los consejos de guerra y justicia, y el «trabajo de mi persona y hazienda, como me cuesta, demas de la composicion ${ }^{30}$. Su carta dedicatoria al rey no ocultaba la esperanza de ver recompensados los servicios de Isaba y del propio Caseda. Inmerso en esta misma lógica de la escritura como servicio, Luis Collado expresó su gratitud por la liberalidad y majestad regias que acompañaban un ascenso por «los grados de la verdadera milicia» ${ }^{31}$.

El modo en que estos autores se autorepresentaron refleja asimismo la muy problemática relación que existía entre la práctica militar (el servicio directo en el ejército) y el servicio teórico ${ }^{32}$. El portugués Luís Mendes de Vasconcellos, que afirmaba haber dejado la milicia «sem satisfação de meus serviços, \& sem ter alcançado algum dos cargos que se devem prover por merecimientos», remitía a la figura ejemplar de Catón para resolver esta situación. Catón, con quien Vasconcellos quería asimilarse, había afirmado precisamente «que muito

${ }^{24}$ OLIVEIRA, 1555: «Prologo». La experiencia militar y marítima del autor en la introducción de António Silva Ribeiro publicada en Lisboa, Ministerio de Marinha, 1969.

${ }^{25}$ CASSOL, 2000: 45 y 49-50.

26 PUDDU, 1989: 160 y 162.

27 HALE, 1983b: 431.

${ }^{28}$ SCARION DE PAVIA, 1598: fol. 4r.

${ }^{29}$ ISABA, 1594: fol. 3r.

30 ISABA, 1594: fol. 2v.

${ }^{31}$ COLLADO, 1592: fol. 95r.

32 VERRIER, 1997: 87-100. ESPINO LÓPEZ, 2001: 484-498. 
mayor utilidade fizera á republica em a escrever que em a obrar na guerra» ${ }^{33}$. Esta controversia entre teoría y práctica, vinculada al debate entre armas y letras, fue una cuestión esencial para diseñar la figura pública de estos autores de artes militares.

En el prólogo a los lectores de El perfeto capitán de Diego de Álaba y Viamont (1589), Antonio de Toledo defendía a éste frente a quienes pudieran preguntar $«[i]$ no aviendo don Diego sido soldado, como puede hazer libro de arte militar?» ${ }^{34}$. Esta defensa desembocaría además en una discusión epistemológica en la que los términos de la pregunta se invirtieron. Antonio de Toledo destacaba la importancia del ingenio y la ciencia para componer los preceptos generales de un arte, minimizando la importancia de la experiencia por su carácter particular y por la posibilidad de recurrir a «libros y historias». En cambio, para Antonio de Toledo «el exercicio hara saber una cosa sola, y essa la que se vio, ò como se vio» y la experiencia se limitaba a pocas regiones, pocos años y pocos sucesos ${ }^{35}$.

En otras muchas obras se abogó sin embargo por un modelo mixto, pues se entendía que la mezcla entre teoría y práctica era la que conducía a la «perfección» del soldado. Martín de Eguiluz, en tono autobiográfico, argumentaba que «con solo aver leydo» nadie podía ser apto para guiar el ejercicio de la guerra. Era imprescindible para el militar «aver visto exercitos, y perdido el temor al enemigo», aunque sólo «juntando las letras sera perfeto» ${ }^{36}$. Francisco de Valdés también reclamaba la mezcla entre teórica y práctica como «mejor y mas noble», y diferenciaba entre soldados capaces de estudiar la milicia y a aquellos otros que perdían su tiempo en juegos y ociosidad, que no habían podido o querido estudiar en su infancia y que carecían del «fundamento devido a la speculation ${ }^{37}$.

En el seno de esta tensión se estaban jugando algunas cuestiones de importancia. Por una parte, ciertos avances tecnológicos como la artillería y la fortificación requerían conocimientos específicos (geometría y cálculo, por ejemplo) y reclamaban modelos de legitimidad propia. Por otra, la representación del militar virtuoso, completo o perfecto incorporaba el estudio de la antigüedad clásica como ocio honesto. La intimidad teórica con la antigüedad servía, así, para expresar diferencias jerárquicas entre simples soldados (cincuenta años de experiencia podían ser superados por un «año de licion, junto con

33 VASCONCELLOS, 1612: «Aos Leytores». El perdido De re militari de Catón había sido usado por Vegecio, que transmitió esta noticia.

34 ÁLABA Y VIAMONT, 1590: «Don Antonio de Toledo à los Letores», fol. 6r.

35 ÁLABA Y VIAMONT, 1590: «Don Antonio de Toledo à los Letores», fol. 6r-v.

${ }^{36}$ EGUILUZ, 1595: fols. 81r-v.

${ }^{37}$ VALDÉS, 1589: 12. 
buen ingenio y observaciones», según Antonio de Toledo ${ }^{38}$ ) y los estrategas o teóricos, que naturalmente ocupaban posiciones más elevadas en el ejército.

El uso, estudio y aplicación de los clásicos fue una herramienta y un signo de diferenciación, y acercaba al militar (representado idealmente en estas ocupaciones) a la figura del político, del estadista o del consejero ${ }^{39}$. En el diálogo de Espejo y disciplina militar recreado por Francisco de Valdés a las orillas de un ameno río, Sancho de Londoño aparece en varias de sus intervenciones mencionando ejemplos clásicos y en un punto concreto declaraba específicamente haber «con harta curiosidad leydo los autores antiquos, y modernos» ${ }^{40}$. Diego de Álaba expresó la misma idea indicando que el buen soldado es quien conoce el «arte militar» como el arquitecto conoce el arte de la arquitectura. Álaba aprovechó también la justificación empleada anteriormente por Diego García de Palacio en sus Dialogos militares (1583): que "sabra mas de la milicia el que sabe de los sucessos y guerras de mas de quatro mil años atras, que el que solo la huviere exercitado por algun tiempo breve» ${ }^{41}$.

Estos «personajes», autores ideales de tratados militares, habitaron un campo de actuación cuyas fronteras, poco delimitadas, acabarán pronto por confluir con la esfera de los hombres de estado ${ }^{42}$. De modo parecido a la literarización o ficcionalización de las autobiografías de soldados que se aprecia a lo largo del siglo XVII, el género de las artes militares parece fusionarse paulatinamente con los tratados de estado. El ingeniero Cristóbal de Rojas, en una dedicatoria a Felipe III en la que explicaba el origen del arte militar y su transmisión escrita desde los lacedemonios hasta los romanos, daba por supuesto que el rey dispondría de sólidos conocimientos militares «por las historias antiguas, y experiencia, que ia tiene dellas por tener çerca dessi tan grandes ministros expertos en el Arte militar» ${ }^{43}$. La Política militar en avisos de generales de Francisco Manuel de Melo (1638) insistía en que una «larga noticia» de los asuntos militares no hacía a un sujeto digno de la dirección del ejército, puesto que ese dominio era el de una «ciencia mayor» ${ }^{44}$. La Política militar de príncipes, dedicada por Juan Baños de Velasco en 1680 al aún joven Carlos II, definía el fundamento teológico, jurídico e histórico de la acción militar española, delimitando aún con mayor claridad el alcance de este

38 ÁLABA Y VIAMONT, 1590: «Don Antonio de Toledo à los Letores», fol. 6v.

39 PUDDU, 1984: 11, 160-162 expone las estrategias paralelas de ennoblecimiento o aristocratización de los militares de la época.

${ }^{40}$ VALDÉS, 1589: 23.

41 ÁLABA Y VIAMONT, 1590: fol. 3v. GARCÍA DE PALACIO, 1583: «Dedicatoria a don Lorenço Suarez de Mendoza».

42 Robert Devereaux, conde de Essex, es un ejemplo bien estudiado del uso político de la erudición clásica. Ver HAMMER, 91/ 2 (Chapel Hill, 1994): 167-180; 190/430 (Oxford, 1994): 26-51. JARDINE y GRAFTON, 129 (Oxford, 1990): 30-78.

${ }^{43}$ ROJAS, 1607: fol. 3r.

44 MELO, 1638: «Dedicatoria al conde de san Lucar». 
alto dominio de decisión y conocimientos militares. Su autor señalaba que ello le había «costado la fatiga de leer lo mas selecto de la Escuela Romana, y Griega, y tambien lo moderno presente $\rangle^{45}$.

La presencia del libro y de la escritura en el ejército moderno es aún una cuestión compleja. David Lawrence ha demostrado para el caso inglés la existencia de un público militar específico, convertido en fructífero mercado editorial ${ }^{46}$. En el caso de portugueses y españoles, este panorama parece confirmarse por las frecuentes alusiones y préstamos que los tratados militares de la época hacen de autores coetáneos suyos ${ }^{47}$. Este público lector también se define en las propias obras analizadas, que hacen asimismo referencias a la comunicación oral de conocimientos militares. Sancho Londoño propuso, por ejemplo la redacción de «un Inchiridion, o breve compendio» en que se organizarían los conocimientos transmitidos por autores clásicos como Vegecio o Eliano, y que serviría para que «todos los Soldados que supiessen leer, viessen, y los demas oyessen leer la buena disciplina militar» ${ }^{48}$.

Bernardino de Escalante también consideraba a los soldados como destinatarios finales de sus Discursos, pues su objetivo era que «los soldados visoños leyendolos, se hagan platicos en breve tiempo» ${ }^{49}$. La aprobación de Rodrigo de Campuzano al Arte militar de Juan de Funes (1582) incidía en la cuestión del público militar al señalar la utilidad del libro «ansi para los Soldados viejos, como doctrina para los venideros $»^{50}$. Por su parte, Scarion de Pavía consideraba que su obra serviría tanto a los soldados en activo como para dar «la instruction que se deve a los nuevos officiales y soldados, que comunmente se llaman visoños» ${ }^{51}$. Afirmaciones como estas indican que conviene replantear detenidamente el papel del escrito en los ejércitos de la época moderna.

La propia tratadística contiene algunas referencias respecto al lugar cotidiano de la escritura. Para Eguiluz, el sargento mayor no puede ser alguien que no sepa «el A b c ni visto jornada de cuenta», sino que debe tener una cierta familiaridad con los cálculos necesarios para formar escuadrones ${ }^{52}$. Tampoco cree que deban confiar en tablas copiadas de libros impresos, pues

45 BAÑOS DE VELASCO, 1680: «Dedicatoria».

${ }^{46}$ LAWRENCE, 2009: 38-46.

47 Para la presencia de obras militares en bibliotecas hispanas, véase ESPINO LÓPEZ 2001: 438-466.

${ }^{48}$ LONDOÑO, 1589: fols. 5r y 43v.

49 ESCALANTE, 1583: «Al illustrissimo señor Cardenal Don Rodrigo de Castro».

${ }^{50}$ FUNES, 1582: «Aprobación».

${ }^{51}$ SCARION DE PAVIA, 1589: fol. 4r.

52 ÁLABA Y VIAMONT, 1590: fols. 106r-108r proporciona algunas de esas tablas por considerar a los sargentos incapaces de hacer los cálculos. Muchas más tablas en FUNES, 1582: fols. $14 \mathrm{r}-25 \mathrm{v}$ y $34 \mathrm{r}-35 \mathrm{v}$. Sobre la diferente formación de oficiales y soldados ESPINO LÓPEZ 2001: 483-486. 
«si se les pierde aquel numerato» quedan a oscuras. Pueden ayudarse, eso sí, de un «librillo de memoria en su faltriquera, que de ordinario le debe traer»o apuntar aquello que sea necesario en la vaina de una espada ${ }^{53}$. El Cartapacio y memoria de cosas importantes a la disciplina militar, un cuaderno manuscrito por Juan de Velasco Villanueva, demuestra una presencia más consistente de la escritura en el dominio militar. Estos apuntes contienen traducciones y extractos de textos teóricos de matemática (Euclides) y de arquitectura de fortificaciones, tablas de medidas y cálculos y una interesante serie de remedios médicos para dolencias propias del campo de batalla. Comenzado en Milán en 1617, y continuado durante años, este cuaderno es un registro de saberes aplicables al ejercicio de la guerra y experiencias personales, tales como un remedio «Para llagas bistas provado y bueno» ${ }^{54}$. Contemplado desde esta óptica, el Abecedario militar compendiado por el ayudante de sargento mayor João de Brito de Lemos (1631), era una mezcla parecida del saber obtenido de los libros y experiencia personal en el ejército: Brito, como muchos de sus contemporáneos, fue soldado y lector de tratados militares, de los cuales reutilizaría páginas enteras en su Abecedario. La lectura y reaprovechamiento de artes militares era una práctica común, como demuestra también la Breve recopilacion de los tratados de Don Sancho de Londoño y de otros autores graves acerca de lo que se vsa agora en el arte militar del sargento Francisco de Leugim (1596).

Teniendo en cuenta esta estructura de la comunicación, en la que se mezclan la conversación con la lectura y con la experiencia de primera mano, no sorprende que en la mayoría de los tratados militares de la Edad Moderna las menciones a la historia del imperio romano sean heterogéneas, superficiales o anecdóticas ${ }^{55}$. El desconocimiento del latín y los usos de segunda mano han sido señalado entre otros por Frédérique Verrier ${ }^{56}$, pero la falta de fidelidad o de precisión no debe confundirnos: la aparición de Roma en esas menciones ha de entenderse de acuerdo con los usos de la escritura y la lectura propios de la cultura militar y en función de las proposiciones que es capaz de articular. Descendiendo de las más altas esferas del gobierno hasta la tropa, se aprecia cierta permeabilidad y curiosidad, a través de las cuales se transmiten los ejemplos clásicos. Al referir a la discusión sobre los orígenes de la guerra Marcos de Isaba indicaba por ejemplo la diversidad de opiniones entre los antiguos y entre los modernos, divergencias que surgían tanto entre «autores y escriptores» «como en platica se trata cada dia entre gente de guerra un po-

\footnotetext{
${ }^{53}$ EGUILUZ, 1595: fol. 22r. Otra mención del librillo en fol. 30r.

${ }^{54}$ VELASCO VILLANUEVA, 1617: fol. 209v.

55 Un ejemplo de esta aproximación en GARCÍA-ALEGRE SÁNCHEZ, 2010, vol. 4.

${ }^{56}$ VERRIER, 1997: 102.
} 
co curiosa ${ }^{57}$. Otro ejemplo muy interesante es el del soldado cobarde y desertor que halagaba la capacidad de escuchar y juzgar del capitán Alonso Enríquez de Guzmán comparándola con la del Gran Capitán, «que fue más esforçado que Aníbal y mas sabio que Salomon y mas franco que Alexandre» ${ }^{58}$. Desde el punto de vista del estudio de los clásicos, además, esta lógica de infiltración y de pérdida de contexto, de uso anecdótico y parcial tampoco es patrimonio exclusivo de las artes militares.

La presencia de los clásicos en el día a día militar es difícil de trazar, pero cuadernos personales como el de Velasco Villanueva nos recuerdan que la experiencia de la guerra no era una actividad ajena a las prácticas lectoras y que quizá esos tiempos ociosos en los que se concibe la escritura militar o el uso de los clásicos estuvieron más cerca de la realidad de lo que pudiera parecer. Sancho de Londoño acababa su tratado indicando que «la memoria forçada, pocas vezes administra lo que hombre dessea, especialemente tan flaca como la mia», pero había incluido en él numerosas referencias a distintos ejércitos y militares de la antigüedad, así como una cita del poeta castellano Gómez Manrique y una larga discusión sobre el silencio de las tropas en Homero (con una cita literal de seis versos, en latín y castellano) ${ }^{59}$. Podemos creer o no a Londoño, pero su testimonio es indicativo del proceso de infiltración del ejemplo clásico en la cultura militar de su tiempo. La Roma que aparecía en ella era fruto de una práctica activa de intervención sobre los textos clásicos y de recomposición y reutilización de los mismos en contextos muy diversos.

\section{DINÁMICAS DE IMITACIÓN}

Si bien la presencia de Roma es constante en todas las obras analizadas ${ }^{60}$, conviene recordar que el lenguaje de imitación y comparación con la antigüedad romana no constituyó una línea discursiva unívoca ${ }^{61}$. Las referencias al imperio romano que aparecen en las artes militares analizadas sirven para modelar ideas acerca del ejército y colocan la actividad militar en una sucesión de grandes imperios (en consonancia con la aproximación política al imperio portugués y español), pero son parte de un tejido más rico. El ejemplo

${ }^{57}$ ISABA, 1594: fol. 1r. En el capítulo XXII Isaba recomendaba la «platica y conversación» como medio de adquirir conocimientos de los oficiales retirados.

58 KENISTON, 1960: 41.

${ }^{59}$ LONDOÑO, 1589: fols. 44r y 40r.

${ }^{60}$ La misma constatación, para los títulos publicados en Venecia entre fines del siglo XV y 1570, en HALE, 1983: 436 y 440.

${ }^{61}$ Sobre la importancia de la tratadística griega en la disciplina ver KLEINSCHMIDT, 63/3 (Lexington, 1999): 603-605. 
de los atenienses y lacedemonios, los macedonios y Alejandro Magno, el de Aníbal y Cartago, las experiencias pasadas de los ejércitos persas o el presente más cercano del imperio turco y de la propia historia europea también son puntos de referencia en la configuración de este campo.

Las primeras páginas de Diego de Álaba y Viamont mezclan innumerables ejemplos griegos y romanos para dar el retrato de un perfecto capitán ${ }^{62}$, mientras que «Lacedemoniens», griegos y romanos son considerados conjuntamente por Francisco de Valdés las «naciones donde mas floreció la milicia» ${ }^{63}$. En otras ocasiones, se compararon las tácticas y formaciones griegas y romanas con el fin de esclarecer la mejor manera de combate ${ }^{64}$. Los ejemplos de la Biblia y los padres de la iglesia sirvieron igualmente para ilustrar las discusiones sobre los orígenes de la guerra y para definir la guerra justa. El portugués Fernando de Oliveira, utilizó exclusivamente once citas bíblicas, dos de santo Tomás y dos de san Agustín para articular el capítulo «Qual he guerra justa» ${ }^{65}$. Cristóbal Mosquera de Figueroa hizo explícita la habitual jerarquía que se aplicaba cuando se recurría al texto sagrado, indicando que los ejemplos de romanos y macedónicos «en nuestros tiempos son de provecho en los exercitos, quando no se hallaren en la sagrada Biblia» ${ }^{66}$. La lógica que relaciona las distintas fuentes empleadas para nutrir de ejemplos a las artes militares es una lógica de acumulación argumental, en la que los distintos pasajes, personajes y situaciones aludidas vienen a demostrar - a costa, en muchas ocasiones, de su contexto original y de su fidelidad textual o histórica- los argumentos del autor.

En medio de este panorama puede distinguirse, no obstante, la presencia de un discurso «romano» específico. Una de las funciones clave de este referente romano, central sin duda durante la segunda mitad del siglo XVI, fue la recuperación (y reconfiguración) de la disciplina militar. La discusión sobre la disciplina romana entre 1560 y 1600 se corresponde con el desarrollo de los acontecimientos militares europeos. Es un referente que sirve para expresar las nuevas formas de organización y disciplina del ejército español $\mathrm{y}$, hacia finales del siglo, las necesidades de reforma y «profesionalización» del mismo. No es tampoco casualidad que los tratados de estos años empleasen el término disciplina en un doble sentido. En efecto, «disciplina» se usaba para referir no sólo al entrenamiento, ejercicio, trabajo constante y respeto a las órdenes, sino también para significar la reflexión teórica y organización sistemática de un conjunto de conocimientos: «lo mismo sera siempre decir,

\footnotetext{
62 ÁLABA Y VIAMONT, 1590: fols. 1r-17v.

63 VALDÉS, 1589: 14.

${ }^{64}$ VASCONCELLOS, 1612: fols. 94r-107r.

${ }^{65}$ OLIVEIRA, 1555: fols. XIV V-XVI V.

${ }^{66}$ MOSQUERA DE FIGUEROA, 1596: fol. 7r.
} 
Arte militar, que disciplina militar», afirmaba ya en 1629 Pedro Barbosa Homen $^{67}$. La disciplina era también una materia teórica, propia del mundo de lo escrito.

Sancho de Londoño consideraba que el ejemplo de los romanos «se deve seguir en todo lo tocante à la buena disciplina militar» y el título de su obra expresaba la necesidad de reconducir la disciplina a meyor y antiguo estado ${ }^{68}$. De hecho, esta visión estaba ya presente en el propio Vegecio, quien destacó la centralidad de la disciplina y la necesidad de volver al buen orden antiguo (contemplado ya a cierta distancia desde el siglo IV d.c.), y no cabe duda de que esta visión se extendió ocasionalmente a su recepción moderna ${ }^{69}$. No obstante, el carácter idealizado del pasado no era completamente ingenuo, pues lo que Londoño proponía concretamente era «imitar a los Romanos segun las armas que en nuestro tiempo se usan ${ }^{70}$. El Discurso de Londoño, escrito por mandato de Alba de 11 de enero de 1568, era claro ejemplo de la doble necesidad que la Edad Moderna tenía por disciplinar el ejército. Londoño reflejaba así tanto las prácticas de entrenamiento usadas por Alba como las posiciones teóricas que este expresó en su Discurso sobre la reforma de la milicia, dotándolas de la legitimidad que confería la referencia al precedente clásico ${ }^{71}$. Londoño también recordó al duque de Alba que el arte militar era difícil de aprender y fácil de olvidar, especialmente en épocas de paz, y que «no solo pues se debria reduzir la buena disciplina militar, mas ponerla en escritto». Catón venía nuevamente a ser un ejemplo junto con Frontino, Eliano, el contemporáneo italiano Valturio, «y despues otros infinitos». Londoño subrayaba de este modo la necesidad de regular y conservar el saber militar y confiaba en que, si «por olvido de los professores della» fuese necesario «restituir» la disciplina militar, pudiese recurrirse a los libros para ello ${ }^{72}$.

El vizcaíno Martín de Eguiluz reconocía que las armas romanas «agora valdrian poco», siendo incluso «cosa de burla y gracioso uso». Para él, la relevancia del ejemplo de los romanos residía en que «peleavan con mucha orden y disciplina, porque estavan muy exercitados y acostumbrados, diestros y obedientes, que es lo que mas importa ${ }^{73}$. Francisco de Valdés recordaba que, según Tito Livio, «avia en Roma muchas escuellas, donde eran enseñados los Tirones que agora llamamos soldados bisoños» y culpaba de la «mala disciplina» de los ejércitos actuales a los oficiales, incapaces de usar con ellos la

${ }^{67}$ BARBOSA HOMEM, 1629: fol. 105v.

${ }^{68}$ LONDOÑO, 1589: fol. 20r.

${ }^{69}$ Sobre la recepción de Vegecio ver CALLEJA, 1982 y ALLMAND, 2011.

${ }^{70}$ LONDOÑO, 1589: fol. $21 \mathrm{v}$.

${ }^{71}$ GONZÁLEZ DE LEÓN, 2009: 53-59.

72 LONDOÑO, 1589: fol. 43v.

${ }^{73}$ EGUILUZ, 1595: fol. 63v. 
«seridad [sic] y rigor [con] que antiguamente eran castigados en los exercitos Romanos ${ }^{74}$. Estas escuelas urbanas en las que «los soldados nuevos se exercitavan y eran enseñados en los preceptos y orden de la guerra», también las recordaba Bernardino de Escalante, contrastándolas con los muchos soldados y oficiales «que se llevan a las provincias del Peru, y Nueva España, y a las Filipinas y otras Islas de aquel mar» y que «no an militado, ni visto jamas campear exercitos $\rangle^{75}$. La disciplina era igualmente necesaria para evitar el ocio y los vicios asociados al descanso de los ejércitos ya veteranos, y autores como Sancho de Londoño ilustrarían esta cuestión refiriendo al conocido descanso - y consiguiente derrota - de las tropas de Aníbal en Capua ${ }^{76}$.

Este tipo de proposiciones de «restauración» o «reforma» no eran simples quejas de militares desengañados. La propuesta de Londoño incluía unos Estatutos concebidos y redactados para ser promulgados como «ordenanzas reales» y las ordenanzas reales de 1598 acabaron por recoger muchas de las reivindicaciones que se encuentran en estos tratados. Estas Ordenanzas, firmadas por Felipe III aún en calidad de príncipe, señalaban que «la buena disciplina militar» de la infantería española se había ido «relaxando y corrompiendo» y referían en dos ocasiones a la buena costumbre antigua. Las ordenanzas regulaban además el sistema de ascensos por orden y antigüedad y la comunicación de los méritos o hazañas especiales (de los maestres de campo al Consejo de Guerra y al Rey, y no libremente) de modo muy parecido al que habían sugerido autores como Juan de Funes ${ }^{77}$. También se contemplaba en ellas el problema de los soldados que «ocupaban y embarazaban» la corte con pretensiones injustas frente a los más beneméritos, crítica expuesta por Marcos de Isaba en términos casi idénticos ${ }^{78}$.

Londoño, Eguiluz y Escalante habían compuesto sus obras en unas décadas de adaptación de los ejércitos a las cambiantes necesidades de la guerra moderna. Las tesis clásicas de una revolución militar procedente en exclusiva del norte de Europa han sido matizadas hace mucho y también se ha mostrado que la tratadística hispana de la época estaba en línea con los avances más significativos del género, tanto en cuestiones técnicas como tácticas ${ }^{79}$. La

${ }^{74}$ VALDÉS, 1589: 10 y 37. No encuentro la referencia en Tito Livio, aunque sí en Vegecio, De re militari, I, 10.

75 ESCALANTE, 1583: «Al illustrissimo señor Cardenal Don Rodrigo de Castro» y dedicatoria «A los muy illustres Señores de la Infanteria Española».

${ }^{76}$ LONDOÑO, 1589: fol. 21v. Este ejemplo también fue usado por BELLAY, 1548: fol. 49v y BOTERO, 1589: 246. Véase Tito Livio, Ab urbe condita, 23, 18, 10-16.

77 Ordenanzas sobre la buena disciplina militar en la infanteria española, 1598, $\mathrm{n}^{\circ}$ 4-9; y FUNES, 1582: fol. 33v.

${ }_{78}$ Ordenanzas sobre la buena disciplina militar en la infanteria española, 1598, $\mathrm{n}^{\circ} 10$; e ISABA, 1594: fol. 38r.

${ }^{79}$ PARKER, 48/2 (Chicago, 1976): 198-201. 
insistencia en el disciplinamiento «a la romana» del ejército y en la consolidación de un arte militar reglado es una demostración más de que esta tratadística se colocaba en la primera línea del renovado panorama militar europeo. La invocación de la conservación o el mantenimiento de modos antiguos permitía avanzar la modernidad y la novedad se presentaba vestida de restitución, como cuando Londoño afirmaba que a los soldados «no solamente se deven guardar los privilegios y exemptiones, que los antiguos les concedieron y guardaron. Pero aun darles mas» ${ }^{80}$.

Gerhard Oestreich sostuvo que la disciplina tuvo una importancia central en la configuración del estado en la Edad Moderna y resaltó la labor fundamental de Justo Lipsio en la divulgación y exaltación de la tradición romana que la articulaba ${ }^{81}$. De esta manera se establecía un vínculo entre la revolución militar y el uso de los clásicos, reforzado por las investigaciones acerca de Mauricio y Guillermo de Nassau, sus reformas y su inspiración en los ejércitos romanos. Resulta más sencillo advertir el impacto general del discurso acerca de la antigua disciplina sobre la concepción del papel del ejército y los gobernantes que descubrir sus aplicaciones particulares (si bien el caso de los Nassau parece bien probado) ${ }^{82}$. Por otra parte, las artes militares ibéricas participan completamente en esta cuestión y se trataba de un discurso que no era completamente nuevo ni se restringía a los Países Bajos. La importancia de la disciplina militar aparece en algunas de las obras más destacadas de estas décadas y no es por ejemplo casual que Giovani Bottero le dedicase un apartado de su noveno libro de la Razón de Estado y que la considerara, parafraseando a Cicerón, «il nervo della militia» ${ }^{83}$. John Hale, por su parte, detectó la preocupación por la disciplina en autores militares italianos anteriores a la reforma de los Nassau ${ }^{84}$.

Existen, sin embargo, autores que minimizan el impacto del referente romano en los desarrollos prácticos efectivos de los ejércitos modernos, o lo consideran irrelevante al interpretarlo como una mera legitimación o dignificación de los oficios militares ${ }^{85}$. Si tenemos en cuenta, como señala Espino ${ }^{86}$, la aplicabilidad del ejemplo romano a las renovadas necesidades de la infante-

${ }^{80}$ LONDOÑO, 1589: fol. 22r.

${ }^{81}$ OESTREICH, 1982.

82 Las principales investigaciones son las de Werner Halweg, pero un buen resumen actualizado en NIMWEGEN 2010: 1-17 y 86-87.

${ }^{83}$ BOTERO, 1589: 246-250. Cicerón, Filípicas, V, 5: «primum nervos belli, pecuniam infinitam».

${ }^{84}$ HALE, 1983b: 436-437.

${ }^{85}$ Participan de este debate específico en torno a la revolución militar Cornelis Schulten o Donald A. Neill. Ver ESPINO LÓPEZ, 2001: 166.

${ }^{86}$ ESPINO LÓPEZ, 2001: 151. 
ría de estas décadas y si, como indica Olaf van Nimwegen ${ }^{87}$, concebimos la existencia de muchas y sucesivas revoluciones militares podemos advertir que el discurso romano funciona en los diferentes niveles de precisión y profundidad que he venido señalando. El referente romano servía también para establecer conexiones entre la vida militar activa y las esferas de la política, el gobierno o los estudios teóricos, una versión ampliada de lo que Hale denominó como «el puente» entre armas y letras ${ }^{88}$.

La infantería era una preocupación central de muchos de los autores examinados, que escribían de aquello que mejor conocían, pero otros aspectos de la actividad militar también se configuraron mirando al pasado romano. En su Cuerpo enfermo Isaba utilizó el ejemplo romano para validar su opinión sobre el papel táctico de la caballería. De este modo, al llegar a la discusión sobre la caballería y la infantería, recomendaba al rey «estimar y tener muy en la memoria a los Romanos y Principes que a la gente de a pie estimaron». Por encima de los ejemplos contrarios de los persas o de Aníbal, la infantería debía ser el principal componente del ejército, «pues esto hazian los antiguos, donde la forma del pelear, casi era bestial, quanta mas necessidad ay agora, siendo todo tan diferente» ${ }^{89}$. Estas mismas ideas aparecen también en Eguiluz, que consideraba «aquel uso de la cavalleria, que los Romanos usavan en sus legiones, repartidos por la infanteria era acertado, y que agora lo usassemos nosotros seria muy importante cosa» ${ }^{90}$.

A pesar de las diferencias existentes entre la navegación en el Mediterráneo y la navegación oceánica, Roma sirvió también como referente para la organización de la armada. En concreto, el ejemplo de Roma servía para argumentar la necesidad de una armada permanente. Esta cuestión aparecía ya en 1555 en la obra de Fernando de Oliveira, que la recoge de Vegecio. Para Oliveira los romanos, una vez pacificado el mar, para adornar su grandeza y no ser cogidos desprevenidos, «sempre tinham no mar, e lugares oportunos, duas frotas esquipadas e prestes, con sua gente darmas, pa acudir onde fosse necessario» ${ }^{91}$. Autores como el artillero español Francisco de Rojas insistirían en esta cuestión. Los términos empleados por Rojas en 1607 demuestran nuevamente la presencia, ahora no explicitada, de Vegecio: «asigurada la mar se trata la guerra com barbaras naçiones» por lo que el pueblo romano no aparejaba la armada cuando se ofrecía la necesidad, sino que «de ordinario la tenía aparejada ${ }^{92}$. Esta reclamación seguiría activa al valorar la estrategia hispana

${ }^{87}$ NIMWEGEN, 2010: 14.

${ }^{88}$ HALE 1983b: 437.

${ }^{89}$ ISABA, 1594: fol. 13r.

${ }^{90}$ EGUILUZ, 1595: fols. 63v-64r.

91 OLIVEIRA, 1555: fol. XIII v.

${ }^{92}$ ROJAS, 1607: fol. 47r. La referencia en Vegecio, De re militari 4, 31. 
en tiempos de Felipe IV. El portugués Pedro Barbosa Homen —ya en 1629 y en un contexto general de ataques holandeses en el Índico- reclamó el establecimiento de armadas permanentes para que «en la sustacia y realidad, se alcançase aquel señorio, y pudiessen con verdad nuestras armadas ygualarse en los efetos, a las antigas de Miseno y Ravena» ${ }^{93}$.

Se ha argumentado repetidamente a favor y en contra de la pervivencia del comportamiento caballeresco, quijotesco o «medieval» en los ejércitos hispanos de fines del siglo XVI sin llegar a una postura unánime ${ }^{94}$. En las artes militares coetáneas, la polémica remitía a una idealizada nobleza romana y su participación en la guerra. Los Diálogos de Escalante alentaban a la nobleza a recibir un verdadero aprendizaje militar, contrastando el modo en que «criavan los nobles Romanos à sus hijos» con los actuales caballeros, «mas ciudadanos de lo que solian ser nuestros passados $\rangle^{95}$. Para el ingeniero portugués Isidoro de Almeida los romanos eran «principes da milicia \& mestres da ordem della», contando con una «militaria» «chea de soldados nobres, \& de sangue» ${ }^{96}$.

Almeida fundamentaba esas afirmaciones refiriendo al «Romano exercito, que levaram Tito Quintio Capitulnio, \& Agripa Furio consules, ha guerra contra os Volscos, \& Aqueios». La narrativa original de Tito Livio (Ab urbe condita 3,66 y 3,69) ofrecía un ejemplo de reclutamiento perfecto, rápido, organizado y con participación de los diferentes estratos sociales, y el episodio reconstruido por Almeida se hacía eco, quizá involuntariamente, de una precisión probablemente superior a las capacidades organizativas reales de la monarquía portuguesa del momento. Escalante recordaba por su parte la batalla de Cannas, en la que se recogieron «tantos anillos de oro (siendo esta insignia de nobleza) que pudô embiar á Carthago tres modios llenos $\rangle^{97}$. La cuestión aparece en Livio $(23,12)$, en Floro (I, 22, «dos modios») y en otros muchos autores, así como en los Facta et dicta memorabilia de Valerio Máximo, que aporta el dato de los «tres modios» (VII, 12, 16). Resulta llamativo que, pese a lo manido de las referencias (en especial la segunda), ambos autores recurriesen a relatos de batallas de la República para tratar de cuestiones virtuosas y nobiliarias.

Un caso específico de comparación entre el pasado romano y la nobleza de la Edad Moderna es el Comentario en breve compendio de disciplina militar

93 BARBOSA HOMEM, 1629: fol. 165r.

94 GARCÍA HERNÁN, 20 (Madrid, 2000): 285-300. THOMPSON, 2007: 15-35.

${ }^{95}$ ESCALANTE, 1583: fol. 1r.

${ }^{96}$ Isidoro de ALMEIDA, Quarto livro de Isidoro de Almeida das instruções militares, Évora, Andre de Burgos, 1573. Cito por la edición de FARIA DE MORAIS, 23 (Lisboa, 1953): 66 y 129.

${ }^{97}$ ESCALANTE, 1583: fol. 1r. 
de Cristóbal Mosquera de Figueroa. La obra fue encargada por Álvaro de Bazán, marqués de Santa Cruz, quien salió favorablemente retratado gracias a la recurrente comparación con valerosos y astutos capitanes del pasado. Sin olvidar la Biblia, Mosquera de Figueroa retrataba idealmente al capitán «moviendose por exemplos de los antiguos, imitando unas vezes a los Romanos, otras a los Griegos, y entre ellos sacando lo mejor de los Macedonios, con ordinaria lecion de buenos libros $\rangle^{98}$. El marqués de Santa Cruz aparecía también como ejemplo de «animo piadoso con gente humilde». Esta característica era reforzada con una cita de Reyes I, 2 (una posible referencia a la benevolencia de David con los hijos de Berzelai) y una comparación entre Alejandro Magno, Anibal y Escipión en la que este último es preferido y alabado por su clemencia y su piedad ${ }^{99}$.

Una de las razones para la popularidad del género de las artes militares radicó, como explicó Geoffrey Parker, en que las innovaciones tácticas (escuadrones más pequeños con combinación de picas y armas de fuego) hacían necesaria una participación más activa de los oficiales menores y una delimitación más clara de la jerarquía y la transmisión de órdenes por parte de los altos cargos ${ }^{100}$. La creciente especialización de funciones y la claridad en la jerarquía de mando se expresó en muchas artes militares a través de la comparación con los cargos y la organización militar romana. Estas comparaciones estaban relacionadas, asimismo, con la lucha por la instauración de un verdadero sistema de ascenso por méritos en los ejércitos.

En orden decreciente de autoridad, Isidoro de Almeida dedicó un capítulo para cada puesto del ejército y discutió sus correspondencias con los cargos antiguos. En este recorrido, inspirado en Vegecio, introdujo también algunas reivindicaciones organizativas importantes. Corrupto y depravado el buen orden de los antiguos, la milicia moderna ponía al mando del «Caporal, ou cabo desquadra» veinticinco o cincuenta hombres para reducir salarios, pero lo aconsejable era que «como os Romanos, a cada dez homens, se dee huma cabeza» ${ }^{101}$. Almeida también recomendaba vivamente recuperar las funciones de los centuriones, necesidad que vinculaba al ejemplo moderno del Infante don Luis que, «quando se fez Mazagam, cabos de cento, ou centuriões ordenou, imitando a boa, \& util ordem dos Romanos». Almeida refiere seguramente a la fortificación de esta ciudad marroquí en 1542 por orden de Juan III, pues había participado directamente como ingeniero en la defensa de esa plaza en 1562. Tenía también experiencia directa del modo en que se hacían las tres guardias nocturnas en África, las cuales elogió indicando que «em nos

${ }^{98}$ MOSQUERA DE FIGUEROA, 1596: fol. 10r.

${ }^{99}$ MOSQUERA DE FIGUEROA, 1596: fols. 33r-v y 37r. El resto de Reyes I, 2 son, no obstante, ejemplos de venganza transmitida de David a Salomón.

${ }^{100}$ PARKER, 48/2 (Chicago, 1976): 202-203.

${ }^{101}$ FARIA DE MORAIS, 23 (Lisboa, 1953): 53. 
os Portugueses, ficou soomente ho costume antiquissimo dos Romanos, no repartir da noite pera as vigias» ${ }^{102}$. La adecuación de ciertas prácticas a las de Roma era síntoma de un ejército bien ordenado.

De hecho, las críticas más habituales de los ejércitos lusos referían a la indisciplina y la falta de orden en el combate ${ }^{103}$. Los historiadores portugueses de la Edad Moderna oscilaron entre el reconocimiento implícito de esta indisciplina y la defensa del ejército portugués. En 1678, Manuel de Faria e Sousa explicaba retrospectivamente el desastre de la campaña africana de D. Sebastián describiendo al ejército portugués como «bisoño y desordenado». Este ejército imitaba «en la riqueza y galas la que llevó contra los Partos Antioco», pero «no fue assi en la disciplina militar, pues antecipadamente se descubrieron argumentos notorios de ruina miserable» ${ }^{104}$. En 1597, Bernardo de Brito había sin embargo defendido que «a gloria militar, \& bom estilo de guerra, fora mais antigo entre Portugueses, que na gente de França» ${ }^{105}$. Curiosamente, Brito defendía este argumento remontándose a un episodio de la Guerra de las Galias, en la que los antiguos franceses habían recibido la ayuda de los portugueses, que habían «trocando em tudo a grossaria, \& barbaro modo de pellejar dos Franceses, em hum estilo mais politico \& seguro» ${ }^{106}$.

Al igual que Almeida y otros, Eguiluz también analizó cargo a cargo, encontrando incluso correspondencias entre el metator castrorum y el capitán general de artillería. Alaba y Viamont había aclarado anteriormente que «es la institucion deste oficio moderna; à cuyo cargo està el govierno de la artilleria, y el fortificar y poner defensas à todas las fortalezas y presidios, y el proveerlos de todo lo demas que fuere necessario» ${ }^{107}$. Eguiluz, por tanto, forzaba las cosas con la comparación. Las atribuciones de «fortificar y poner defensas» podían asemejarse a las funciones de elegir el lugar y delimitar el recinto del campamento, pero la diferencia entre metator y metator castrorum ${ }^{108}$ que Eguiluz inventó para diferenciar al maestre de campo general y al capitán general de artillería ni siquiera correspondía con el uso romano ${ }^{109}$. Incluso de modo ficticio, el ejército romano servía para expresar la gradación jerárquica ideal que debía tener todo ejército. De modo parecido, Francisco de Valdés recordaba

102 FARIA DE MORAIS, 23 (Lisboa, 1953): 67-68 y 77 respectivamente. Los datos biográficos de Almeida en la introducción.

${ }^{103}$ BEBIANO, 1997: 536-540.

${ }^{104}$ FARIA E SOUSA, 1678-1680: Tomo III, 20.

105 BRITO, 1597: fol. 336r

106 BRITO, 1597: fol. 335v.

107 ÁLABA Y VIAMONT, 1590: fol. 151r.

${ }^{108}$ EGUILUZ, 1595: fols. 65r y 67r.

${ }^{109}$ El término aparece en Cicerón, Filípicas, 11, 5, pero la tradición textual que pudo inspirar a Eguiluz para hablar del castrorum metator es muy amplia. Ver DAREMBERG y SAGLIO, 1877-1919: s.v. 
que el nombre de sargento mayor «se dize por causa que en cada tercio o regimiento que es como una legion Romana, ay un sargento el qual es superintendente sobre todos los otros sargentos de su Tercio» para precisar, poco más adelante, que este oficio no había existido entre los antiguos romanos ${ }^{110}$.

La dinámica de la imitación del ejemplo romano tuvo un eje fundamental en la lucha por la recuperación o reinstauración de una disciplina supuestamente perdida y que resultaba, entre 1560 y 1600 una cuestión de suma importancia para la infantería del momento. En torno a ese núcleo central de reclamaciones se aprecia, no obstante, que los ejemplos de la historia romana permitían vehicular un pensamiento mucho más complejo sobre los ejércitos modernos y que estos recursos fueron empleados para abordar cuestiones tan diferentes como la caballería, la guerra marítima, la jerarquía o el papel de la nobleza en el ejército. La utilísima flexibilidad del ejemplo clásico no estaba sin embargo exenta, como mostraré en la siguiente y última sección, de importantes contradicciones.

\section{EJEMPLARIDAD Y MODERNIDAD: DE LO IDEAL A LO CONTRADICTORIO}

La ejemplaridad romana no era una cuestión sencilla y existe, como he indicado, un debate historiográfico sobre la efectividad real del ejemplo clásico. De hecho, también para los contemporáneos la revolución de la técnica militar parecía poder reducir la contribución de Roma a una mera curiosidad, pues el descubrimiento de la pólvora y sus efectos sobre la fortificación, el asedio y la estrategia establecían una distancia insalvable con épocas anteriores. En 1620, Francis Bacon propuso, en una frase bien conocida, que la pólvora (junto a sus compañeras, la imprenta y la brújula, todas ellas desconocidas de los antiguos) había significado «el cambio en la apariencia y el estado de las cosas en todo el mundo» ${ }^{111}$. Los autores que recurrían al ejemplo romano fueron los primeros que advirtieron y comentaron sus posibles limitaciones y contradicciones, siendo bien conscientes de que debían reinterpretarlo y adecuarlo a sus necesidades. Como ya he mostrado, Londoño, Eguiluz, Álaba y, Viamont y otros reconocían perfectamente la diferencia entre Roma y su presente y, no cabe duda, de que para ellos la brecha generada por la pólvora afectaba notablemente al balance de autoridad entre antiguos y modernos.

Si hacemos justicia al análisis de los múltiples usos del referente romano en los textos de las artes militares, éstas parecen conducirnos a una contradicción insalvable. El ejemplo romano es a veces un ideal construido únicamente para subrayar el presente, sin apenas base en la propia tradición clásica. En otras oca-

110 VALDÉS, 1589: 9-10.

${ }^{111}$ BACON, Instauratio magna, Londres, Ioannem Billium, lib. 1, p. CXXIX. En SPEDDING, ELLIS, y HEATH, 1857-1874, vol. 4: 114-115. 
siones, las propias artes militares admiten las diferencias con la antigüedad, absolutamente insalvables, pero no dejan por ello de utilizarla. En obras como la de Vasconcellos o la de Âlaba y Viamont algunas partes están plagadas de citas clásicas y argumentos extraídos de una antigüedad, mientras que otras niegan la validez de esos ejemplos o, lo que es aún más intrigante, los ignoran. Aparecen así largas páginas sobre proyectiles, sobre composiciones de la pólvora, sobre fortificaciones o formaciones de batalla en las que la antigüedad ha desaparecido.

Los efectos reales de la artillería y las armas de fuego han sido contextualizados, matizados y discutidos por parte de los historiadores ${ }^{112}$, y de hecho la propia invención de la pólvora fue una materia muy debatida en la época. El artillero y matemático italiano Niccolò Tartaglia era la fuente principal (a través de él se citaba también a Vitrubio) para quienes apuntaron la posibilidad de que Arquímedes hubiera usado no sólo catapultas y otras armas arrojadizas sino también artillería. Este debate fue debidamente trasladado a la península por artilleros como Luis Collado, Diego de Álaba y Viamont o Cristóbal de Rojas ${ }^{113}$. De algún modo, con mayores o menores reticencias, todos ellos recogieron la posibilidad de que la pólvora hubiese sido una invención romana, lo que demuestra que, incluso en esta cuestión, el prestigio romano seguía siendo un argumento de cierto peso.

Nicolás Maquiavelo contribuyó decisivamente a consolidar el debate entre las armas modernas y los ejércitos antiguos al analizar la relación entre artillería y virtud en sus Discorsi. Aparte de denunciar la falta de coordinación en los ejércitos modernos, en los que «no se encontró ahora ninguno de nuestros Capitanes que imite los órdenes antiguos o corrija los modernos», Maquiavelo dedicaba un capítulo a discutir si «la artillería impide que no se pueda usar la antigua virtud». La discusión estaba organizada en torno a un contrafactual: había que determinar si en caso de haber existido la artillería, los romanos hubieran podido «conquistar (pigliare) las provincias, hacer tributarios a los pueblos». Tras un sinnúmero de ejemplos, Maquiavelo concluía que la utilidad de la artillería era definitiva «cuando se mezcla con la antigua virtud, pero sin ella, contra un ejército virtuoso es inutilísima» ${ }^{114}$.

Estas consideraciones, quizás aún sostenibles para las décadas iniciales del siglo XVI, abrieron un prolongado debate, que en ocasiones corrió paralelo a la propia recepción de las obras de Maquiavelo (entre las que se incluyen, por supuesto su Arte della guerra). Gilbert y Anglo han señalado la enorme per-

112 GILBERT, 1986: 13-15. HALE, 1983a: 390-410.

${ }^{113}$ COLLADO, 1592: fols. 5r-v. ÁLABA Y VIAMONT, 1590: fols. 5 r-v. ROJAS, 1607: fols. $89 \mathrm{r}-\mathrm{v}$.

114 MAQUIAVELO, 1550, libro II, caps. 16 y 17: 157 y 163. HÖRNQVIST, 55/1 (Chicago, 2002): 148-191 llama la atención sobre el antiromanismo florentino de comienzos del siglo XVI y la deliberada omisión del ejemplo romano en ciertas obras de Maquiavelo. 
sistencia del esquema que antepone la superioridad romana a los desarrollos en las armas de fuego. Hasta comienzos del siglo XVII y a pesar de la fractura evidente que suponían los desarrollos técnicos, los debates se articularon como una prolongación o expansión de la problemática apuntada por Maquiavelo 115 .

Naturalmente, existieron también numerosos críticos. Para Roger Williams la nueva fortificación de muros gruesos y bajos conocida como trace italienne hacía inclinarse la balanza en sentido contrario: "Alejandro, César, Escipion y Anibal han sido los más valiosos y famosos guerreros que nunca existieron, pero [...] nunca habrían conquistado países con tal facilidad si hubieran estado fortificados como Alemania, Francia y los Países Bajos» ${ }^{116}$. Entre los autores ibéricos, Luís Mendes de Vasconcellos, «conhecendo quanta mais força tem as nossas peças de artelheria, que as antigas fundas dos Romanos» se propuso contradecir las tesis de Lipsio, otro de los grandes defensores de la superioridad romana.

Vasconcellos, que publicó su Arte militar en 1612, no podía admitir que el «docto Lipsio» hubiera argumentado la superioridad de la honda frente a los arcabuces $^{117}$. Esta refutación era parte de una comparación más general en la que Vasconcellos, también en contra de Lipsio, defendía la superioridad de la milicia moderna frente a las antiguas griegas y romanas. La postura de Vasconcellos (aunque no tanto sus enrevesadas demostraciones) parece más que lógica. Resulta significativo, sin embargo, que una parte fundamental de su argumento demuestre precisamente que la moderna milicia ya ha incorporado la división y el orden de los romanos: esa era la característica que interesaba. Además de ello, Vasconcellos admitía que el ejército romano (una vez más un referente idealizado a partir de fuentes idealizadas) era superior al moderno por la «sevèra inteireza com que soldados, \& capitães observavão os preceitos, \& leys da sua milicia» ${ }^{118}$.

El carácter paradójico del debate se observa también en autores como Juan de Carrión Pardo, que definió «la mosquetería» como el «arma que mas importa» ${ }^{119}$ en su tiempo, pero defendió a la vez la necesidad de seguir el ejemplo romano. En concreto, Carrión trataba de buscar una solución para evitar que, debido a la desproporción entre piqueros y arcabuceros, los soldados se viesen obligados a cargar la arcabucería al hombro. Recurrió entonces a «las leyes, y loables costumbres de la guerra» de los romanos, que proponían una

115 ANGLO, 2005: 511-513. GILBERT, 1986: 29-30.

116 Roger WILLIAMS, A Briefe discorse on warre, Londres, Thomas Orwirn, 1590. Citado en BURKE, 1979, vol. 13: 201.

117 VASCONCELLOS, 1612: fol. 105r.

118 VASCONCELLOS, 1612: fol. 106v.

${ }^{119}$ CARRIÓN PARDO, 1595: fol. 8r. 
proporción de dos terceras partes de picas y una de arcabuces. Naturalmente, Carrión era consciente de que los romanos no tenían arcabuceros, pero mantenía que el ejemplo seguía siendo perfectamente válido, ya que «en su lugar usavan de ballesteros» ${ }^{120}$.

La fructífera contradicción que generaba el ejemplo de Roma se apreciaba igualmente en la proyección colonial. De un modo parecido a lo que ocurría con la pólvora, la innegable novedad de los «mundos descubiertos» permitía abrir una brecha de autoridad entre la antigüedad y el presente. La superioridad militar europea era aparente en América, y resultaba habitual integrar a los indígenas o salvajes con los bárbaros de la antigüedad, pero pronto también se apreciaron las particulares exigencias de la lucha contra los pobladores de algunas regiones, como las tratadas por Bernardo Vargas Machuca en su Milicia de las Indias (1599). La lógica indicaba que «[...] habiendo tanta diferencia así en armas como en las demás cosas, diferente práctica y milicia será fuerza tengamos en aquellas partes», pero ello no impedía que pudiese comentar un dicho de Julio César para medir cuánto debe ser el atrevimiento del caudillo o comparar directamente el «acometimiento» de Alejandro Magno con el de los españoles contra los indios, que «como gente bárbara», se retiraban ante las acometidas vigorosas, incluso en situaciones de constante inferioridad numérica ${ }^{121}$.

\section{CONCLUSIONES}

Tomadas en su conjunto, las artes militares analizadas demuestran que el estudio del pasado romano durante la Edad Moderna permitió por una parte su recuperación y por otra la generación (de modo paralelo e indiferenciado) de una cierta distancia crítica con la antigüedad que se observaba. En 1954 Robert Bolgar ya indicó que durante la Edad Moderna la tradición clásica pasó de ser considerada una «lección necesaria» a un «contraste saludable» ${ }^{122}$. La ironía o «paradoja» implícita en el redescubrimiento del pasado fue señalada también por John Pocock, quien recordó que los humanistas traspasaron su proyecto original, de modo que «la copia y la imitación se hicieron imposibles y apareció el problema del pasado como un campo de estudio independiente» ${ }^{123}$. Anthony Grafton también ha puesto de relieve la existencia de dos grupos de humanistas, uno que asumió «la relevancia y la accesibilidad incuestionable» del mundo antiguo y otro que admitía las dificultades de reconstruir el pasado, que podían llegar a demostrar la «irrelevan-

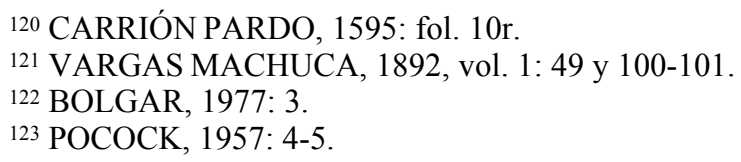


cia de la experiencia y los preceptos antiguos para los problemas modernos» ${ }^{124}$ y más recientemente Peter Burke ha señalado la presencia constante de una tradición de «anti-ejemplaridad» en la Edad Moderna ${ }^{125}$.

Una manera de solventar estos usos duales o paradójicos del pasado es situarlos en un panorama evolutivo. Naturalmente, el uso de los clásicos no fue igual entre el primer renacimiento y el siglo XVIII y esto puede explicar el diferente peso relativo de la comparación con la antigüedad o la crítica de la misma. En todo caso, el uso del referente romano en las artes militares muestra que estas dos tendencias, antes de resolverse en uno u otro sentido, podían funcionar conjuntamente. La importancia de la disciplina y la novedad de la pólvora convivían sin problema en la visión militar del momento, que tenía una capacidad destacada para la agregación acumulativa de fuentes y ejemplos no siempre coherentes. La aparente y extraña anulación de las diferencias temporales entre los militares de la república y los de época imperial, así como la capacidad de aunar los ejemplos romanos, griegos, persas, turcos y otros modernos de distintas naciones europeas sin preguntarse por la coherencia final del conjunto, ni por las contradicciones inherentes es muestra de un pensamiento casuístico y retórico ajeno a otras lógicas de cohesión argumental.

A lo largo de estas páginas he tratado de mostrar que los autores militares ibéricos no sólo participaron de esta lógica cultural, sino que fueron agentes clave en la recepción del pasado imperial romano y en su transformación en marco de referencia para debatir el alcance y las necesidades del gobierno de la guerra en las monarquías de la Península Ibérica. Gracias a la recepción y apropiación activa del pasado, consiguieron transmitir demandas particulares y promover visiones concretas sobre el papel que debía jugar el ejército y el pensamiento militar en el desarrollo de las formaciones políticas modernas. Junto a la discusión de cuestiones técnicas y prácticas de alcance más reducido, las artes militares constituyen, en suma, una expresión fundamental del papel que la guerra tuvo como expresión cultural y política de la edad moderna.

\section{BIBLIOGRAFÍA}

Álaba y Viamont, Diego de, El perfeto capitan, Madrid, Pedro Madrigal, 1590.

Allmand, Christopher, The De re militari of Vegetius: the reception, transmission and legacy of a Roman text in the Middle Ages, Cambridge, Cambridge University Press, 2011.

Anglo, Sydney, Machiavelli: the first century. Studies in enthusiasm, hostility, and irrelevance, Oxford, Oxford University Press, 2005.

124 GRAFTON, 1991: 26-27.

${ }^{125}$ BURKE, 2011: 48-59. 
Baños de Velasco, Juan, Politica militar de principes, Madrid, Francisco Sanz, 1680.

Barbosa Homem, Pedro, Discursos de jurídica y verdadera razón de estado, Coimbra, Nicolao Carvallo, 1629.

Bebiano, Rui, «Literatura militar da Restauração», Penélope, 9/10 (1993): 83-98.

Bebiano, Rui, A pena de Marte. Escrita da guerra em Portugal e na Europa (sécs. XVI-XVIII), Tesis doctoral, Faculdade de Letras, Universidade de Coimbra, 1997.

Bellay, Guillaume du, Instructions sur le faict de la guerre, París, Michel Vascosan, Galiot du Pré, 1548.

Black, Jeremy, European warfare, 1494-1660, Londres, Routledge, 2002.

Black, Jeremy, Rethinking military history, Londres, Routledge, 2004.

Bolgar, Robert R. The Classical Heritage and its Beneficiaries from the Carolingian age to the end of the Renaissance, Cambridge, Cambridge University Press, 1977 [1954].

Botero, Giovanni, Della ragion di stato libri dieci,Venecia, Gaspar Gioliti,1589.

Brito, Bernardo de, Monarchia Lusytana, Alcobaça, Alexandre de Siqueira \& Antonio Alvarez, 1597.

Brito de Lemos, João de, Abecedario militar, Lisboa, Pedro Craesbeeck, 1631.

Burke, Peter, « Exemplarity and anti-exemplarity in Early Modern Europe», en Lianeri, Alexandra (Ed.), The Western Time of Ancient History. Historiographical encounters with the Greek and Roman pasts, Cambridge, Cambridge University Press, 2011,

Calleja, María Teresa, Edición crítica y traducción del "Epitoma rei militares" de Vegetius, Libros I y II, Tesis doctoral, Universidad Complutense de Madrid, 1982.

Campbell, Brian, Greek and Roman Military Writers. Selected Readings, Londres, Routledge, 2004.

Carrión Pardo, Juan de, Tratado como se deven formar los quatro esquadrones, en que milita nuestra nacion española, Lisboa, António Alvares, 1595.

Cassol, Alessandro, Vita e scrittura. Autobiografie di soldati spagnoli del Siglo de Oro, Milán, LED, 2000.

Collado, Luis, Platica manual de artilleria, Milán, Pablo Gotardo Poncio, 1592.

Daremberg, Charles Victor y Saglio, Edmond, Dictionnaire des Antiquités grecques et romaines, 10 vols, París, Hachette, 1877-1919. <http://dagr.univ-tlse2.fr/sdx/dagr/ index.xsp>.

Eguiluz, Martín de, Milicia, discurso, y regla militar, Amberes, Pedro Bellero, 1595 [1592].

Escalante, Bernardino de, Dialogos del Arte Militar, Sevilla, Andrea Pescioni, 1583.

Espino López, Antonio, Guerra y cultura en la época moderna. La tratadística militar hispánica de los siglos XVI y XVII: libros, autores y lectores, Madrid, Ministerio de Defensa, 2001.

Espino López, Antonio, «La historiografía hispana sobre la guerra en la época de los Austrias. Un balance, 1991-2000», Manuscrits, 21 (Barcelona, 2003): 161-191. 
Faria de Morais, A., «Arte militar quinhentista»; en Boletim do Arquivo Histórico Militar, 23 (Lisboa, 1953).

Faria e Sousa, Manuel de, Europa portuguesa, 3 vols, Lisboa, António Craesbeeck, 1678-1680.

Funes, Juan de, Libro intitulado arte militar en el qual se declara que sea el oficio de Sargento mayor, Pamplona, Thomas Porralis, 1582.

García de Palacio, Diego, Dialogos militares, México, Pedro Ocharce, 1583.

García Hernán, David, «La función militar de la nobleza en los orígenes de la España Moderna», en Gladius, 20 (Madrid, 2000): 285-300.

García Hernán, Enrique, «Don Sancho de Londoño. Perfil biográfico», Revista de Historia Moderna: Anales de la Universidad de Alicante, 22 (2004): 7-72.

García Hernán, Enrique y Maffi, Davide (Coords.), Guerra y sociedad en la Monarquía Hispánica: política, estrategia y cultura en la Europa moderna, 1500-1700, Madrid, Laberinto y Consejo Superior de Investigaciones Científicas, 2006.

García-Alegre Sánchez, Genoveva, «La presencia de Julio César en los tratados españoles De re militari del siglo XVI», en Maestre Maestre, José María, Pascual Barea, Joaquín y Charlo Brea, Luis (Eds.), Humanismo y pervivencia del mundo clásico IV. Homenaje a Antonio Prieto, Alcañiz y Madrid, Instituto de Estudios Humanísticos, 2010: 1975-1980.

González Castrillo, Ricardo, El arte militar en la España del siglo XVI, S.L., Edición personal, 2000.

González de León, Fernando, The road to Rocroi: class, culture and command in the Spanish army of Flanders, 1567-1659, Leiden, Brill, 2009.

González de León, Fernando, «"Doctors of the military discipline”: technical expertise and the paradigm of the Spanish soldier in the early modern period», Sixteenth Century Journal, 27, 1 (1996): 61-85.

Gracián de Alderete, Diego, De re militari, Barcelona, Claudio Bornat, 1566.

Grafton, Anthony, Defenders of the text. The traditions of scholarship in an age of science, 1450-1800. Cambridge (Massachusetts), Harvard University Press, 1991.

Hale, John Rigby, «Gunpowder and the Renaissance: an essay in the history of ideas», en Renaissance war studies, Londres, Hambledon, 1983a, págs. 389-420

Hale, John Rigby, «Printing and the military culture of Renaissance Venice», en Renaissance war studies, Londres, Hambledon, 1983b, págs. 429-470.

Hammer, Paul E. J., «The Earl of Essex, Fulke Greville and the employment of scholars»; en Studies in Philology, 91/2 (Chapel Hill, 1994): 167-180.

Hammer, Paul E. J., «The use of scholarship: The secretariat of Robert Devereux, second Earl of Essex, c. 1585-1601», English Historical Review, 190: 430 (Oxford, 1994): 26-51.

Hörnqvist, Mikael, «Perché non si usa allegare i Romani: Machiavelli and the Florentine militia of 1506», Renaissance Quarterly, 55/1 (Chicago, 2002): 148-191. 
Isaba, Marcos de, Cuerpo enfermo de la milicia española, Madrid, Guilhermo Druy, 1594.

Jardine, Lisa y Grafton, Anthony, «'Studied for action': How Gabriel Harvey read his Livy», Past and Present, 129 (Oxford: 1990): 30-78.

Jiménez Estrella, Antonio y Andújar Castillo, Francisco (Coords.), Los nervios de la guera. Estudios sociales sobre el ejército de la monarquía hispánica (siglos XVIXVIII): nuevas perspectivas, Granada, Comares, 2007.

Keniston, Hayward (ed.), Libro de la vida y costumbres de don Alonso Enríquez de Guzmán, Madrid, Atlas, 1960.

Kleinschmidt, Harald, «Using the gun: manual drill and the proliferation of portable firearms», The Journal of Military History, 63, 3 (Lexington, 1999): 601-630.

Lawrence, David R., The complete soldier. Military books and military culture in early Stuart England, 1603-1645, Leiden, Brill, 2009.

Leugim, Francisco, Breve recopilacion de los tratados de Don Sancho de Londoño y de otros autores graves acerca de lo que se vsa agora en el arte militar, Valencia, Pedro Patricio, 1596.

Londoño, Sancho de, Discurso sobre la forma de reduzir la disciplina Militar, a meyor y antiguo estado, Bruselas, Roger Velpius, 1589.

Maquiavelo, Nicolás, Discorsi di Nicolo Machiavegli ... sopra la prima deca di Tito Livio, Venecia, Bartholomeo Zanetti da Casterzago, 1550 [1537].

Martínez Oyarzábal, Elena, «El libro y la literatura militar en la segunda mitad del siglo XVII», en García Hernán, Enrique y Maffi, Davide (Coords.), Guerra y sociedad en la Monarquía Hispánica: política, estrategia y cultura en la Europa moderna, 1500-1700, Madrid, Laberinto y Consejo Superior de Investigaciones Científicas, 2006; 817-842.

Melo, Francisco Manuel de, Política militar en avisos de generales, Madrid, Francisco Martínez, 1638.

Mendoza, Bernardino de, Comentarios ... de lo sucedido en las Guerras de los Payses Baxos, Madrid, Pedro Madrigal, 1592.

Mendoza, Bernardino de, Theorica y práctica de la guerra, Madrid, Viuda de P. Madrigal, 1596 [1595].

Merino Peral, Esther, El arte militar en la época moderna: los tratados "de re militari" en el Renacimiento, 1536-1671, Madrid, Ministerio de Defensa, 2002.

Mosquera de Figueroa, Cristóbal, Comentario en breve compendio de disciplina militar, Madrid, Luis Sánchez, 1596.

Nimwegen, Olaf van, The Dutch army and the military revolutions, 1588-1688, Woodbridge, Boydell, 2010.

Oestreich, Gerhard, Neostoicism and the early modern state, Cambridge, Cambridge University Press, 1982.

Oliveira, Fernando, A arte da guerra no mar, Coimbra, Iohão Alverez, 1555. 
[Ordenanzas sobre la buena disciplina militar en la infanteria española dadas en San Lorenzo, 8 de Agosto de 1598], 1598.

Parker, Geoffrey, «The "Military Revolution", 1560-1660—a myth?», The Journal of Modern History, 48/2 (Chicago, 1976), págs. 195-214.

Parker, Geoffrey, «The "military revolution", 1955-2005: from Belfast to Barcelona and the Hague», The Journal of Military History, 69: 1 (2005, Lexington): 205-209.

Pocock, John G. A., The Ancient Constitution and the feudal law, Cambridge, Cambridge University Press, 1957.

Puddu, Raffaele, El soldado gentilhombre. Autorretrato de una sociedad guerrera: la España del siglo XVI, Barcelona, Argos Vergara, 1984.

Rojas, Cristóbal de, Sumario de la milicia antigua y moderna con la orden de hacer un ejército de naciones y marchar con él, 1607. [Biblioteca Nacional de Madrid, Mss. 9286.]

Saunders, J. W., «The stigma of print. A note on the social bases of Tudor poetry»; en Essays in Criticism, 1 (Oxford, 1951): 139-164.

Scarion de Pavia, Bartolomé, Doctrina militar, Lisboa, Pedro Craesbeeck, 1598.

Spedding, J., Ellis, R. L. y Heath, D. D. (eds.), The works of Francis Bacon, 14 vols., Londres, Longmans, 1857-1874.

Thompson, I. A. A. «El soldado del imperio: una aproximación al perfil del recluta español en el Siglo de Oro», Manuscrits, 21 (Barcelona, 2003), págs. 17-38.

Valdés, Francisco de, Espejo y disciplina militar, S.L., 1589.

Vargas Machuca, Bernardo de, Milicia y descipción de las Indias, 2 vols., Madrid, Victoriano Suárez, 1892.

Vasconcellos, Luís Mendes de, Arte militar dividida em tres partes, Alenquer, Vicente Alvarez, 1612.

Velasco Villanueva, Juan, Cartapacio y memoria de cosas importantes a la disciplina militar, 1617. [BNM Mss. 4388.]

Verrier, Frédérique, Les armes de Minerve: l'humanisme militaire dans l'Italie du XVIe siècle, París, Université de Paris-Sorbonne, 1997.

White, Lorraine, «The experience of Spain's early modern soldiers: combat, welfare and violence», War in History, 9/1 (Great Bardfield, Essex, 2002): 1-38.

White, Lorraine, «Guerra y revolución militar en la Iberia del siglo XVII», Manuscrits, 21 (Barcelona, 2003): 63-93.

Recibido: 08/04/2013

Aceptado: 02/12/2013 